\title{
Comparative analysis of copy number detection by whole-genome BAC and oligonucleotide array CGH
}

\author{
Nicholas J Neill, Beth S Torchia, Bassem A Bejjani, Lisa G Shaffer, Blake C Ballif*
}

\begin{abstract}
Background: Microarray-based comparative genomic hybridization $(\mathrm{aCGH})$ is a powerful diagnostic tool for the detection of DNA copy number gains and losses associated with chromosome abnormalities, many of which are below the resolution of conventional chromosome analysis. It has been presumed that whole-genome oligonucleotide (oligo) arrays identify more clinically significant copy-number abnormalities than whole-genome bacterial artificial chromosome (BAC) arrays, yet this has not been systematically studied in a clinical diagnostic setting.

Results: To determine the difference in detection rate between similarly designed BAC and oligo arrays, we developed whole-genome BAC and oligonucleotide microarrays and validated them in a side-by-side comparison of 466 consecutive clinical specimens submitted to our laboratory for aCGH. Of the 466 cases studied, 67 (14.3\%) had a copy-number imbalance of potential clinical significance detectable by the whole-genome BAC array, and $73(15.6 \%)$ had a copy-number imbalance of potential clinical significance detectable by the whole-genome oligo array. However, because both platforms identified copy number variants of unclear clinical significance, we designed a systematic method for the interpretation of copy number alterations and tested an additional 3,443 cases by BAC array and 3,096 cases by oligo array. Of those cases tested on the BAC array, 17.6\% were found to have a copy-number abnormality of potential clinical significance, whereas the detection rate increased to $22.5 \%$ for the cases tested by oligo array. In addition, we validated the oligo array for detection of mosaicism and found that it could routinely detect mosaicism at levels of 30\% and greater.
\end{abstract}

Conclusions: Although BAC arrays have faster turnaround times, the increased detection rate of oligo arrays makes them attractive for clinical cytogenetic testing.

\section{Introduction}

Molecular cytogenetic techniques such as array-based comparative genomic hybridization $(\mathrm{aCGH})$ have revolutionized cytogenetic diagnostics and, in turn, the clinical management of patients with developmental delays and multiple congenital anomalies [1,2]. These rapid, highresolution, and highly accurate techniques have identified numerous previously unrecognized chromosomal syndromes [3-8], refined critical regions for established genetic defects [9], and broadened our view of the "normal" diploid genome [10]. In addition, aCGH has given the clinician a greater appreciation of variability in the

\footnotetext{
* Correspondence: ballif@signaturegenomics.com

Signature Genomic Laboratories, Spokane, WA, USA
}

clinical presentation of many well-described conditions $[11,12]$ and allowed for the discovery of new conditions with relatively mild phenotypes [13,14]. Furthermore, the application of aCGH has created a paradigm shift in genetics that has moved the description and discovery of genetic conditions from the "phenotype-first" approach, in which patients exhibiting similar clinical features are identified prior to the discovery of an underlying etiology, to a "genotype-first" approach, in which a collection of individuals with similar copy-number imbalances can be examined for common clinical features [15].

Originally, targeted microarrays constructed from bacterial artificial chromosomes (BAC) were developed for the clinical laboratory because of their ability to clearly 
identify copy number changes in discrete regions of the human genome known to play a role in genetic disease [16]. This "less is more" idea prevailed in the early years of clinical aCGH because the technology was new and proof of principle was required before it could be adopted for more widespread diagnostic use. Furthermore, the identification of copy number alterations of unclear clinical significance was considered undesirable to the diagnostician, the ordering physician, and the patient's family. Recently, the coverage of microarrays has expanded to include more comprehensive coverage of the human genome, leading many to suggest that whole-genome BAC or oligo arrays are the next step in the continued improvement in the detection rate of cytogenetic abnormalities.

It has been presumed that whole-genome oligonucleotide arrays, because they have higher resolutions, would detect more copy number aberrations than wholegenome BAC arrays. However, to our knowledge, there has not been a systematic comparison of these two whole-genome copy number screening technologies in a clinical diagnostic environment. Therefore, to determine which platform is most effective in identifying clinically significant DNA copy number alterations, we designed a whole-genome BAC array and a whole-genome oligo array and compared the results in a blinded study of 466 clinical diagnostic specimens. In addition, we prospectively evaluated 3,443 patients by the whole-genome BAC array and 3,096 patients by the whole-genome oligo array and compared the detection rates of clinically significant abnormalities and those of unclear clinical significance. Finally, we validated our oligo array with 48 cases to determine the level of mosaicism that can be reliably detected and compared that level to our previously published cases analyzed using the BAC array.

\section{Materials and methods}

\section{Whole-genome BAC array design and aCGH}

We constructed a whole-genome BAC array designed for clinical diagnostic use using $>4,600$ BAC clones. All clones were validated by FISH prior to inclusion on the array using previously described validation procedures [16]. Contigs of 3-6 overlapping clones were selected to cover 1,543 genetic loci, including $>150$ known microdeletion/microduplication syndromes and increased density of coverage in the 5-10 Mb surrounding the subtelomeric and pericentromeric regions of the genome. In addition, we placed contigs to cover $>500$ functionally significant genes such as transcription factors and other genes known to play important roles in development. This coverage also includes genome-wide representation with at least one contig in nearly every chromosomal band at the resolution of an 850-band karyotype. The mean gap size for the whole-genome $\mathrm{BAC}$ array is $\sim 1.6 \mathrm{Mb}$. Microarray manufacturing and $\mathrm{aCGH}$ analysis using the whole-genome BAC array were performed as previously described [13]. BAC arrays were analyzed after a dye-swap, two-experiment analysis [16], using sex-mismatched controls. Results were then displayed using custom BAC aCGH analysis software (Genoglyphix $^{\mathrm{mm}}$; Signature Genomic Laboratories, Spokane, WA).

\section{Whole-genome Oligonucleotide Array Design and aCGH}

Oligonucleotide-based microarray analysis was performed using a custom-designed, 105K-feature whole-genome microarray manufactured by Agilent Technologies (Santa Clara, CA) with one probe every 10 $\mathrm{kb}$ in regions of interest-microdeletion/microduplication syndromes, the pericentromeric regions, subtelomeres and genes involved in important developmental pathways-for an average of 50 oligos per clinical locus. In addition, to achieve backbone coverage, we placed a probe, on average, every $35 \mathrm{~kb}$ throughout the rest of the genome between the regions of interest. Genomic DNA labeling was performed as described for BAC arrays, whereas array hybridization and washing were performed as specified by the manufacturer (Agilent Technologies). A dye swap was not performed for the oligo arrays, and sex-matched controls were used. Arrays were scanned and analyzed as previously described [17]. Results of aberration calls consisting of five or more consecutive oligos were then displayed using custom oligonucleotide aCGH analysis software (Genoglyphix $^{\mathrm{Tm}}$; Signature Genomic Laboratories). The use of five consecutive oligos achieved a resolution of $40 \mathrm{~kb}$ in the regions of interest and a resolution of 140 $\mathrm{kb}$ in the backbone.

\section{Decision Algorithm for Clinically Significant Copy Number Reporting}

We developed a decision algorithm for classifying clinically significant copy number alterations, alterations of unclear clinical significance, and alterations of no currently known clinical significance. Alterations that were associated with established chromosomal syndromes, were large and affected a significant amount of gene content, or were part of a complex rearrangement such as an unbalanced translocation, insertion, or marker chromosome were characterized as clinically significant. Alterations with unclear clinical significance were most commonly those which were not currently associated with a syndrome but which affected gene content which may have contributed to the patient's phenotype and those which could not be precisely refined by the BAC array. Alterations were considered to have no known clinical significance if they were small, affected minimal 
gene content, and/or were present in regions where common copy-number variation was known to occur in the general population. Signature's own Genoglyphix Chromosome Aberration Database (GCAD) was used as a reference to assist in the interpretation of each alteration. GCAD is a database of $>11,000$ chromosomal abnormalities identified in $>9,500$ patients out of $>40,000$ patients evaluated by our laboratory and contains detailed statistics of each observed alteration (breakpoint coordinates, size, gene content, etc.) as well as clinical information pertaining to patient referral.

\section{Fluorescence in situ Hybridization (FISH)}

When possible, all copy number alterations detected by microarray analysis were visualized by interphase and/or metaphase FISH using a BAC probe located within the region of gain or loss. FISH was performed as previously described [18].

\section{Patient Clinical Testing}

To validate the custom-designed $105 \mathrm{k}$ oligo array compared to the whole-genome BAC array, 466 cases were run side-by-side in a platform comparison study. In each case, the clinically validated BAC array results were used for interpretation and reporting. Specimens with known chromosome abnormalities, parental specimens, and prenatal cases were excluded from the analysis.

In addition, we conducted a prospective study of 3,443 consecutive BAC microarray analyses and 3,096 consecutive oligo microarray analyses in our clinical laboratory. The array platform used for testing in each case was chosen by the referring physician at the time of sample submission to our clinical diagnostic laboratory. Cases with previously known chromosomal abnormalities, parental samples, and prenatal specimens were again excluded from the data collection.

\section{Mosaicism Assessment}

The ability of the oligo platform to detect mosaicism was assessed on 48 patients previously known to carry mosaic abnormalities at levels as low as $5 \%$. The alterations studied included a variety of interstitial, terminal, and whole-chromosome copy-number abnormalities, as well as marker chromosomes. The mosaic alteration in each patient was initially assessed by BAC array and the level of mosaicism determined by interphase FISH analysis when possible. In a separate experiment, mosaicism was assessed using a dilution of cells from a male with trisomy 21 with normal male control cells, as previously described [19]. After FISH verification of the dilutions, DNA was extracted from the diluted cells, labeled and hybridized to the custom-designed oligo array as described above.

\section{Results}

\section{Platform comparison study}

From the 466 cases analyzed by the BAC array, using the previously described algorithm, we excluded 347 cases that only had aberrations located within regions that contained no genes and/or aberrations that had been established to be normal population variants by Signature Genomic Laboratories or identified in the Toronto Database of Genomic Variants (DGV, http:// projects.tcag.ca/variation/). After these cases were excluded, 138 copy number alterations in 119 cases (25.5\% of the original 466 cases) remained that required FISH analysis. These aberrations included subtelomeric and pericentromeric gains for which FISH was required to exclude an unbalanced translocation or a marker chromosome. After FISH was performed, 60 aberrations in 52 cases were classified as normal variants because marker chromosomes and derivative chromosomes were not identified and because these alterations were located within regions where common copy number variation is known to occur. Thus, alterations of potential clinical significance according to our algorithm were identified in 67 cases, a detection rate of $14.4 \%$. Of these cases, 56 (12.0\%) were considered to contain clinically significant copy number alterations (Table 1), and 11 (2.4\%) were considered to contain copy number variants of unclear clinical significance for which parental analyses were recommended to further clarify the abnormality (Table 2). aCGH and FISH analysis performed on parental samples revealed that six alterations of unclear significance were inherited from a carrier parent and one was a de novo event in the proband. The origin of the other four unclear alterations could not be determined.

Using the oligo array, we identified 1,337 copy number variations among the same 466 cases. Using the algorithm previously described, we excluded 1,172 aberrations that were located within regions that had no gene content or those that were common copy number variants. After these exclusions were made, 165 aberrations in 138 cases $(29.6 \%)$ remained that required FISH analysis. After FISH analysis was performed, aberrations of potential clinical significance were identified in 73 cases, a detection rate of $15.7 \%$. Of these, the same $56(12.0 \%)$ cases that were identified by the BAC platform were considered to contain clinically significant alterations (Table 1) and 17 (3.7\%) were determined to contain copy number variants of unclear clinical significance.

Table 3 shows the six cases for which aberrations of unclear clinical significance were identified by the oligo array but not by the BAC array. In all six cases, the aberrations either fell within the gaps in the BAC array coverage or were only partially covered by one or more BACs. The average size of the alterations that were not 
Table 1 Cases with Alterations of Clinical Significance Identified by BAC and Oligo aCGH

\begin{tabular}{|c|c|c|c|c|c|c|c|c|}
\hline Pt. \# & Chr & Band & Start pos. & End pos. & Gain/Loss & Size & \# of BACs & \# of Oligos \\
\hline 21637 & chr16 & p11.2 & $29,563,985$ & $30,066,187$ & LosS & 502,202 & 5 & 46 \\
\hline 21992 & chr16 & p11.2 & $29,563,985$ & $30,066,187$ & Loss & 502,202 & 5 & 46 \\
\hline 22013 & chr16 & p11.2 & $29,563,985$ & $30,066,187$ & LosS & 502,202 & 5 & 46 \\
\hline 21993 & chr10 & $\mathrm{q} 25.2 \mathrm{q} 25.3$ & $114,306,207$ & $114,925,368$ & LosS & 619,161 & 3 & 36 \\
\hline 21756 & chr2 & q35 & $219,418,281$ & $220,060,969$ & LosS & 642,688 & 2 & 43 \\
\hline 22002 & chr2 & q37.3 & $239,664,393$ & $240,400,008$ & Loss & 735,615 & 3 & 82 \\
\hline 22334 & chr10 & $\mathrm{q} 25.2 \mathrm{q} 25.3$ & $114,024,053$ & $115,677,301$ & Gain & $1,653,248$ & 3 & 53 \\
\hline 21688 & chr16 & p13.11p12.3 & $15,056,257$ & $16,742,812$ & Gain & $1,686,555$ & 3 & 61 \\
\hline 21667 & chr17 & $\mathrm{p} 12$ & $14,052,297$ & $15,742,271$ & Gain & $1,689,974$ & 3 & 67 \\
\hline 21896 & chr4 & q35.2 & $189,407,487$ & $191,133,809$ & Loss & $1,726,322$ & 8 & 147 \\
\hline 22269 & chr2 & $q 12.3 q 13$ & $107,945,041$ & $109,784,684$ & LOSS & $1,839,643$ & 6 & 102 \\
\hline 21640 & chr19 & q13.42 & $59,272,450$ & $61,239,237$ & Gain & $1,966,787$ & 8 & 135 \\
\hline 22117 & chr9 & q33.1 & $118,991,777$ & $121,063,590$ & Gain & $2,071,813$ & 3 & 67 \\
\hline 22066 & chr8 & p12p11.21 & $38,303,146$ & $40,515,492$ & Gain & $2,212,346$ & 6 & 104 \\
\hline 21786 & chr1 & q21.1 & $144,973,942$ & $147,421,814$ & Gain & $2,447,872$ & 5 & 63 \\
\hline 22237 & chr1 & q21.1 & $144,973,942$ & $147,421,814$ & Gain & $2,447,872$ & 5 & 63 \\
\hline 22310 & chr22 & q11.21 & $17,299,742$ & $19,770,655$ & Loss & $2,470,913$ & 13 & 205 \\
\hline 22050 & chr22 & q11.21 & $17,007,819$ & $19,770,655$ & Loss & $2,762,836$ & 13 & 208 \\
\hline 21936 & chr1 & q21.1 & $144,973,942$ & $147,966,185$ & Gain & $2,992,243$ & 5 & 65 \\
\hline 21719 & chr2 & q31.1 & $169,823,689$ & $172,870,083$ & LOSS & $3,046,394$ & 8 & 119 \\
\hline 22128 & chr4 & q34.3 & $179,065,989$ & $182,435,119$ & Loss & $3,369,130$ & 3 & 91 \\
\hline 22006 & chr17 & $p 11.2$ & $16,723,071$ & $20,145,604$ & LOSS & $3,422,533$ & 18 & 311 \\
\hline 22174 & chr1 & $q 41 q 42.12$ & $221,260,860$ & $224,709,317$ & Loss & $3,448,457$ & 9 & 178 \\
\hline 21971 & chr22 & $q 11.23 q 12.2$ & $24,025,269$ & $28,008,109$ & LOSS & $3,982,840$ & 3 & 111 \\
\hline 22073 & chr15 & $\mathrm{q} 11.2 \mathrm{q} 13.1$ & $21,208,177$ & $26,194,049$ & LOSS & $4,985,872$ & 11 & 281 \\
\hline 21687 & chr16 & $q 12.2 q 21$ & $51,912,655$ & $57,173,018$ & LosS & $5,260,363$ & 15 & 261 \\
\hline 21975 & chr5 & p15.2p14.3 & $13,514,464$ & $18,988,928$ & Loss & $5,474,464$ & 3 & 122 \\
\hline 21555 & chr7 & p22.3p22.1 & 153,644 & $6,230,285$ & Gain & $6,076,641$ & 32 & 434 \\
\hline 21547 & chr2 & $\mathrm{q} 24.3 \mathrm{q} 31.1$ & $168,702,606$ & $174,842,496$ & LOSS & $6,139,890$ & 11 & 226 \\
\hline 21755 & chr11 & p12p11.2 & $37,540,680$ & $43,940,573$ & LosS & $6,399,893$ & 14 & 298 \\
\hline 21761 & chr3 & p14.1p12.3 & $70,738,914$ & $77,275,908$ & Loss & $6,536,994$ & 6 & 151 \\
\hline 22151 & chr15 & $\mathrm{q} 11.2 \mathrm{q} 13.1$ & $18,809,804$ & $26,194,049$ & Gain & $7,384,245$ & 14 & 331 \\
\hline 22322 & chr8 & p21.3p12 & $22,954,212$ & $30,630,828$ & Loss & $7,676,616$ & 9 & 224 \\
\hline 21889 & chr2 & q33.1q34 & $202,901,021$ & $211,366,732$ & Gain & $8,465,711$ & 13 & 281 \\
\hline 21723 & chr5 & $\mathrm{q} 23.1 \mathrm{q} 23.3$ & $121,487,477$ & $130,306,377$ & LOSS & $8,818,900$ & 4 & 204 \\
\hline 22337 & chr1 & p36.22p36.13 & $9,476,880$ & $19,436,653$ & Loss & $9,959,773$ & 21 & 436 \\
\hline 21795 & chr1 & p34.2p32.3 & $41,201,837$ & $55,191,500$ & Gain & $13,989,663$ & 17 & 440 \\
\hline 20986 & chr12 & p13.33p12.3 & 84,918 & $17,505,135$ & Gain & $17,420,217$ & 46 & 800 \\
\hline 21957 & chr11 & $q 23.3 q 25$ & $116,478,434$ & $134,419,382$ & Gain & $17,940,948$ & 40 & 784 \\
\hline 21596 & chr1 & $q 25.1 q 32.1$ & $173,519,967$ & $203,663,817$ & Gain & $30,143,850$ & 25 & 814 \\
\hline 22055 & chr3 & p14.1p13 & $71,164,161$ & $71,958,845$ & LosS & 794,684 & 3 & 46 \\
\hline $21566^{*}$ & chr17 & p13.2p13.1 & $6,081,457$ & $6,904,679$ & Loss & 823,222 & 3 & 14 \\
\hline 21558 & chr22 & q13.33 & $48,567,185$ & $49,517,230$ & Loss & 950,045 & 6 & 54 \\
\hline 21770 & chr8 & p23.3 & 202,505 & $1,411,517$ & Loss & $1,209,012$ & 5 & 96 \\
\hline 22254 & chr8 & p23.2 & $2,604,280$ & $3,966,809$ & LosS & $1,362,529$ & 9 & 140 \\
\hline 21937 & chr7 & $q 11.23$ & $72,404,049$ & $73,771,409$ & Loss & $1,367,360$ & 10 & 158 \\
\hline
\end{tabular}


Table 1: Cases with Alterations of Clinical Significance Identified by BAC and Oligo aCGH (Continued)

\begin{tabular}{lllrrrrrc}
\hline $\mathbf{2 1 7 1 0}$ & chr15 & q13.2q13.3 & $28,741,818$ & $30,186,356$ & Loss & $1,444,538$ & 3 & 64 \\
\hline $\mathbf{2 1 7 2 2}$ & chr15 & q13.2q13.3 & $28,741,818$ & $30,226,376$ & Loss & $1,484,558$ & 3 & 65 \\
\hline $\mathbf{2 1 7 3 9}$ & chr15 & q13.2q13.3 & $28,741,818$ & $30,226,376$ & Loss & $1,484,558$ & 3 & 65 \\
\hline $\mathbf{2 1 7 8 7}$ & chr15 & q13.2q13.3 & $28,741,818$ & $30,226,376$ & Loss & $1,484,558$ & 3 & 65 \\
\hline $\mathbf{2 1 8 9 7 *}$ & chr5 & p15.2 & $8,511,592$ & $9,888,817$ & Gain & $1,377,225$ & 34 & 3 \\
\hline $\mathbf{2 1 8 8 4}$ & chrX & q28 & $152,676,750$ & $153,059,428$ & Gain & 382,678 & 39 \\
\hline $\mathbf{2 1 5 9 2}$ & chrX & p22.33q28 & 701 & $154,888,083$ & Gain & $154,887,382$ & 325 & 6888 \\
\hline $\mathbf{2 2 0 8 7}$ & chrY & p11.32 & 262,578 & $57,715,879$ & Gain & $57,453,301$ & 49 & 49 \\
\hline $\mathbf{2 2 2 8 5}$ & chrX & p21.1 & $31,759,551$ & $31,830,811$ & Loss & 71,260 & 2 & 11 \\
\hline $\mathbf{2 2 2 4 4}$ & chr22 & q13.33 & $49,342,961$ & $49,514,486$ & Loss & 171,525 & 2 & 56 \\
\hline
\end{tabular}

*additional alterations identified by oligonucleotide aCGH.

detected by the BAC array was $1.12 \mathrm{Mb}$ (range: $289 \mathrm{~kb}$ $1.42 \mathrm{Mb})$.

In two cases, the oligo microarray identified additional complexity that was not recognized by the BAC array. In patient 21566, the BAC array identified one interstitial deletion of $17 \mathrm{p} 13.2 \mathrm{p} 13.1$, whereas oligo array analysis identified that deletion and an additional interstitial deletion in the same band (data not shown). In patient 21897, the BAC array identified a 6.8 Mb terminal deletion of 5p, whereas oligo array analysis identified that deletion and a 1.4 Mb duplication proximal to the deleted region (Figure 1).

\section{Prospective Diagnostic Comparison}

Of the 3,443 diagnostic specimens analyzed using our whole-genome BAC array, 605 (17.6\%) had copy number alterations. Using the previously described algorithm, 365 (10.6\%) had abnormalities that were classified as clinically significant, whereas 240 (6.9\%) had copy number variants of unclear clinical significance.

Of the 3,096 diagnostic specimens analyzed using our whole-genome oligo array during the same time period, 698 (22.5\%) had copy number alterations. Using the previously described algorithm, 477 (15.9\%) of these cases were determined to contain alterations considered to be clinically significant and 221 (7.0\%) were determined to contain copy number variants of unclear clinical significance (Table 4).

The increased number of cases with clinically significant alterations detected by the oligo array was found to be statistically significant using a Fisher's Exact Test $(\mathrm{OR}=1.5359, \mathrm{p}<.0001)$. The increased number of cases with alterations of unclear significance detected by the oligo array was not statistically significant $(\mathrm{OR}=$ 1.0259, $\mathrm{p}=0.8090)$.

\section{Mosaicism Assessment}

All but three of the 48 previously known mosaic alterations were detected by the oligo array. FISH analysis estimated that the proportion of uncultured cells carrying the alteration was $24 \%$ in the first case, while the proportion in cultured cells was $6 \%$. In the second case, $5 \%$ of cells were found to carry the alteration by FISH (data not shown). The proportion of cells carrying the alteration in the third case could not be determined because FISH confirmation was not possible on the

Table 2 Cases with Alterations of Unclear Significance Identified by BAC and Oligo aCGH

\begin{tabular}{|c|c|c|c|c|c|c|c|c|c|}
\hline Pt. \# & Chr & Band & Start pos. & End pos. & Gain/Loss & Size & \# of BACs & \# of Oligos & Inheritance \\
\hline 22365 & chr9 & $\mathrm{p} 23$ & $9,881,385$ & $9,984,838$ & Loss & 103,453 & 2 & 15 & Paternal \\
\hline 21702 & chr16 & p12.2 & $21,486,897$ & $21,641,890$ & LOSS & 154,993 & 2 & 16 & Paternal \\
\hline 21883 & chr16 & p12.1 & $21,974,396$ & $22,338,234$ & Gain & 363,838 & 3 & 49 & Maternal \\
\hline 21860 & chr16 & p12.1 & $21,907,270$ & $22,338,234$ & LOSS & 430,964 & 3 & 50 & Unknown \\
\hline 22009 & chr22 & $\mathrm{q} 11.21$ & $19,069,125$ & $19,770,655$ & Loss & 701,530 & 4 & 70 & Paternal \\
\hline 22102 & chr16 & p13.11 & $14,981,044$ & $16,166,985$ & Gain & $1,185,941$ & 3 & 60 & Maternal \\
\hline 22246 & chr10 & $\mathrm{p} 11.22$ & $31,591,310$ & $32,792,762$ & Loss & $1,201,452$ & 2 & 40 & Unknown \\
\hline 21893 & chrX & p11.32 & $45,930,652$ & $46,382,140$ & Gain & 451,488 & 3 & 34 & Maternal \\
\hline 22273 & chrX & $q 28$ & $153,355,101$ & $154,317,591$ & Gain & 962,490 & 5 & 46 & Unknown \\
\hline 10245 & chr3 & p14.1 & $67,727,841$ & $69,101,769$ & Loss & $1,373,928$ & 2 & 25 & Unknown \\
\hline 22348 & chr13 & $\mathrm{q} 22.2$ & $74,989,699$ & $75,378,640$ & Loss & 388,941 & 3 & 51 & De novo \\
\hline
\end{tabular}


Table 3 Cases with Alterations of Unclear Significance Detected by Oligo Array but not Identified by BAC Array

\begin{tabular}{rllrrrrr}
\hline Pt. \# & Chr & Band & Start pos. & End pos. & Gain/Loss & Size & \# of Oligos \\
\hline $\mathbf{9 7 5 6}$ & chr2 & p25.1 & $11,097,126$ & $12,515,559$ & Loss & $1,418,433$ & 19 \\
\hline $\mathbf{9 8 8 6}$ & chr1 & q42.12 & $222,702,622$ & $223,461,255$ & Loss & 758,633 & 16 \\
\hline $\mathbf{1 0 1 4 1}$ & chr2 & q32.3q33.1 & $196,729,308$ & $197,880,950$ & Loss & $1,151,642$ & 30 \\
\hline $\mathbf{1 0 1 1 4}$ & chr15 & q26.3 & $97,299,441$ & $97,745,782$ & Gain & 446,341 & 16 \\
\hline $\mathbf{1 0 2 9 2}$ & chr7 & p14.3 & $33,202,932$ & $33,492,136$ & Loss & 289,204 & 5 \\
\hline $\mathbf{1 0 0 1 9}$ & chr2 & p16.3 & $51,079,474$ & $51,993,245$ & Gain & 913,771 & 13 \\
\hline
\end{tabular}

sample received by our laboratory. Certain alterations, such as tetrasomy $12 \mathrm{p}$, were successfully detected in proportions of cells as low as $10 \%$ by the oligo array, although this low threshold of detection was facilitated by the tetrasomic nature of the rearrangement; the $4: 2$ ratio of patient to control DNA in this case was more readily detected than the 3:2 ratio typically associated with duplications. Figure 2 shows a $2.77 \mathrm{Mb}$ interstitial deletion at $16 \mathrm{q} 12.1$ present in $23 \%$ of cultured metaphase cells that was detected by the oligo array.

In the dilution series of trisomy 21 cells, shifts in the aCGH data were distinguishable down to levels as low as $10 \%$, but could only be readily detected at a level of $30 \%$ or greater (Figure 3 ). As the proportion of trisomy
21 cells was increased from $10 \%$ to $30 \%$, the average $\log _{2}$ ratio of chromosome 21 increased from 0.08 to 0.21 . During the prospective diagnostic comparison, 16 cases analyzed using the BAC array contained mosaic alterations, whereas only 12 mosaic cases were identified using the oligo array (Table 5). The increased number of mosaic abnormalities detected by the BAC array was determined to be not statistically significant $(\mathrm{OR}=$ 1.1999, $\mathrm{p}=0.7066)$.

\section{Discussion}

BAC and oligo array platforms each have unique advantages and disadvantages in a diagnostic setting; these may include turnaround times, genomic coverage, and

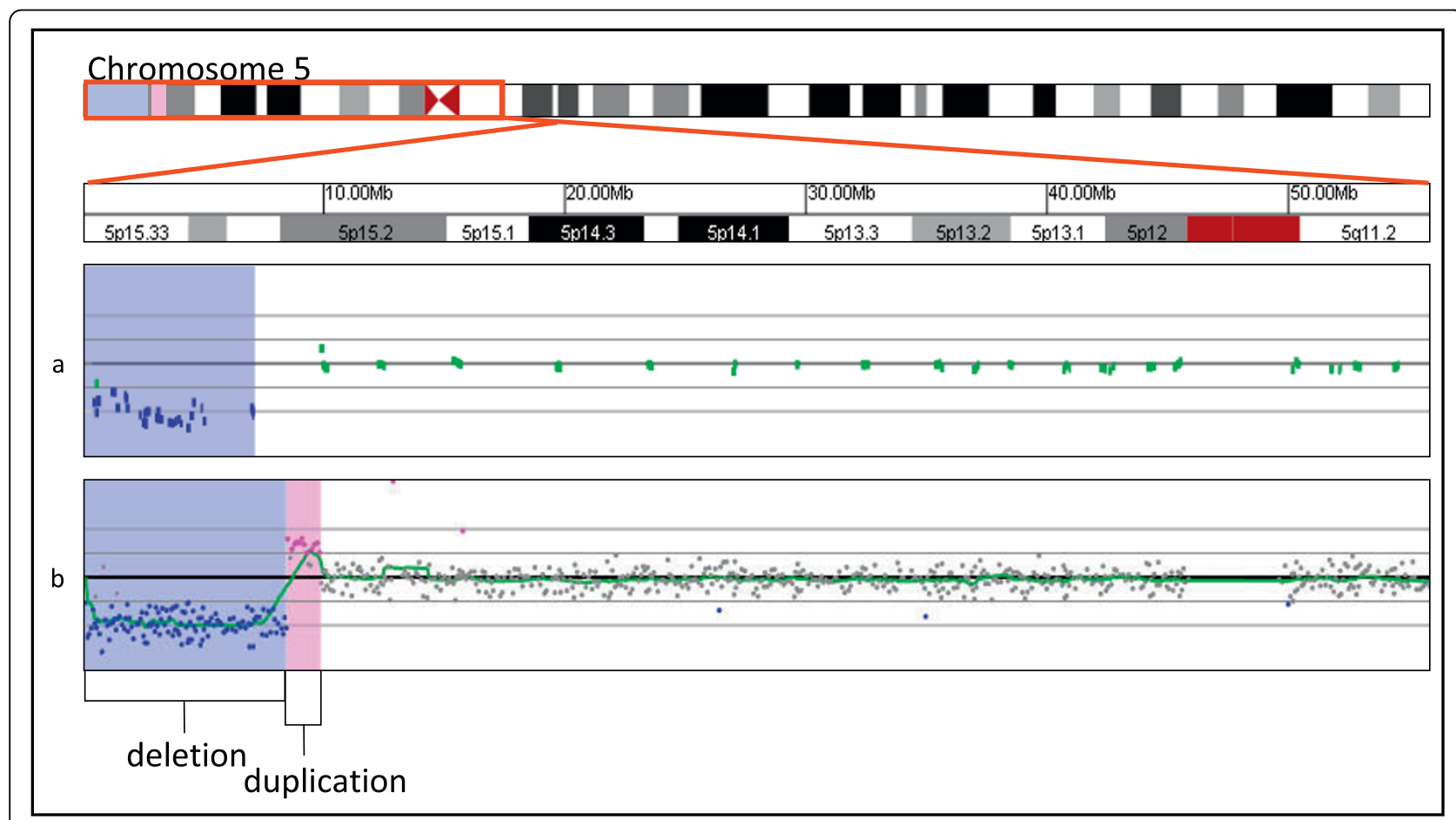

Figure 1 Identification by oligonucleotide microarray of additional complexity missed by BAC microarray. (A) BAC microarray results showing a single-copy loss of 34 BAC clones from the terminus of 5p, approximately 6.8 Mb in size (chr5: 387,034-7,150,950, based on UCSC 2006 hg 18 assembly). Probes are ordered on the $x$ axis according to physical mapping positions, with the p-arm probes to the left and $q$-arm probes to the right. (B) shows oligonucleotide microarray results of the terminal deletion shown in (A) in addition to single-copy gain of 29 probes from 5p, approximately $1.38 \mathrm{Mb}$ in size (chr5: 8,511,592-9,888,817, based on UCSC $2006 \mathrm{hg} 18$ assembly). Probes are ordered as in the BAC array. Regions shaded in blue represent deletions detected by microarray, whereas duplications are shaded in pink. 
Table 4 Summary of the Prospective Diagnostic Comparison

\begin{tabular}{lcc}
\hline & BAC & Oligo \\
\hline Total & 3,443 & 3,096 \\
\hline Abnormal & $605(17.6 \%)$ & $698(22.5 \%)$ \\
\hline Significant & $365(10.6 \%)$ & $477(15.4 \%)$ \\
\hline Unclear & $240(7.0 \%)$ & $221(7.1 \%)$ \\
\hline Mosaic & $16(0.5 \%)$ & $12(0.4 \%)$ \\
\hline
\end{tabular}

costs. One of the most important characteristics of each platform is the detection rate of clinically significant alterations. Our results demonstrate that our wholegenome oligo array was able to detect such alterations in $15.4 \%$ of patients tested, compared to the BAC array detection rate of $10.6 \%$, a statistically significant difference (Fisher's Exact Test, $\mathrm{p}<0.0001$ ). The alterations that constitute the $4.8 \%$ difference in detection rate between the BAC and oligo arrays are either too small to be detected by the BAC array but are not below the resolution of the oligo platform (Figure 4) or fall within gaps in the BAC array coverage (Figure 5). Figure 4 shows a $44 \mathrm{~kb}$ deletion of $17 \mathrm{p} 13.3$ detected in a patient referred to our laboratory for convulsions. This deletion encompasses the first exon of PAFAH1B1 (LIS1). While it is not known whether this deletion results in a null allele or simply a truncated gene product, hemizygous deletions and mutations of this gene are found in patients with isolated lissencephaly type 1 (OMIM
607432) and have been linked to epileptic seizures and convulsions [20,21]. Although RP11-135N5 provides coverage of this region on the BAC array, FISH analysis using this clone could not confirm the deletion in any cells because of the deletion's small size compared to the FISH probe used. Thus, this clinically significant deletion could only have been reliably detected using the oligo platform. Although oligo-based aCGH has the power to detect alterations smaller than the size of a BAC probe, BAC-based aCGH has an advantage in that the analysis makes evident the appropriate probe to be used for FISH confirmation. In addition, this probe is usually readily available because of its inclusion on the microarray platform and will have a high rate of successful confirmation. When oligonucleotide-based aCGH is performed, BAC probes must be specifically selected for the FISH confirmation of each small abnormality that is detected. Once a probe has been selected, it must also be specially prepared or ordered before FISH can be performed. This process increases both the time it takes to perform FISH confirmation of oligo aCGH results and the cost associated with the analysis.

Figure 5 shows a $2.9 \mathrm{Mb}$ deletion of $6 \mathrm{q} 14.1$ detected in a patient referred to our laboratory for developmental delay and dysmorphic features. This deletion encompasses eight genes: PHIP, HMGN3, LCA5, SH3BGRL2, ELOVL4, TTK, BCKDHB, two of which are known to be associated with human disease [22-24]. Although this

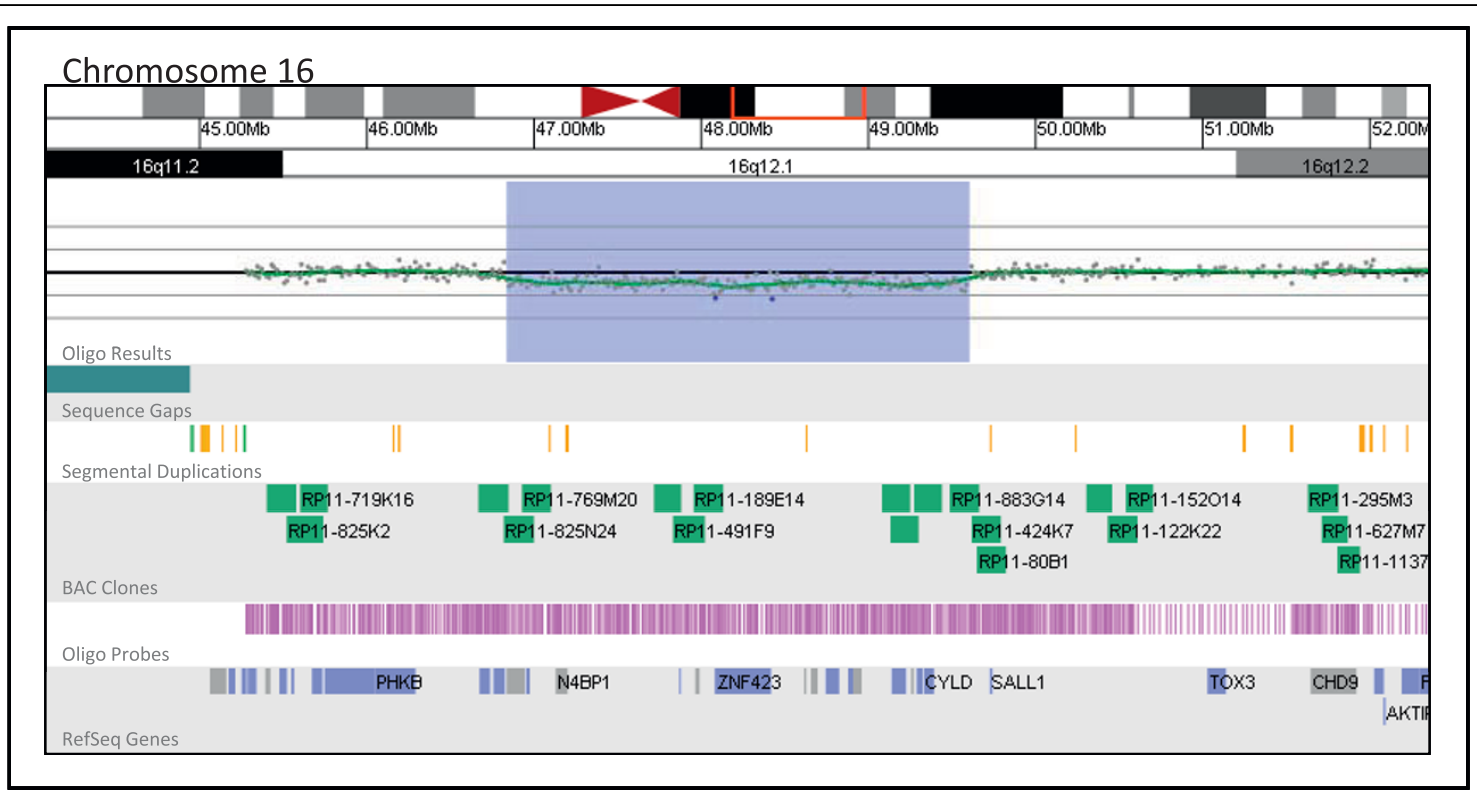

Figure 2 Oligonucleotide microarray analysis of a mosaic $\mathbf{1 6 q} 1 \mathbf{1 2 . 1}$ deletion (shaded blue region). The zoomed-in microarray plot shows a single-copy loss of 289 probes from 16q12.1, approximately 2.77 Mb in size (chr16: 46,837,260-49,605,054, based on UCSC 2006 hg 18 assembly). Probes are ordered on the $x$ axis according to physical mapping positions, with the most proximal 16q11.2 probes to the left and the most distal $16 \mathrm{q} 12.2$ probes to the right. 


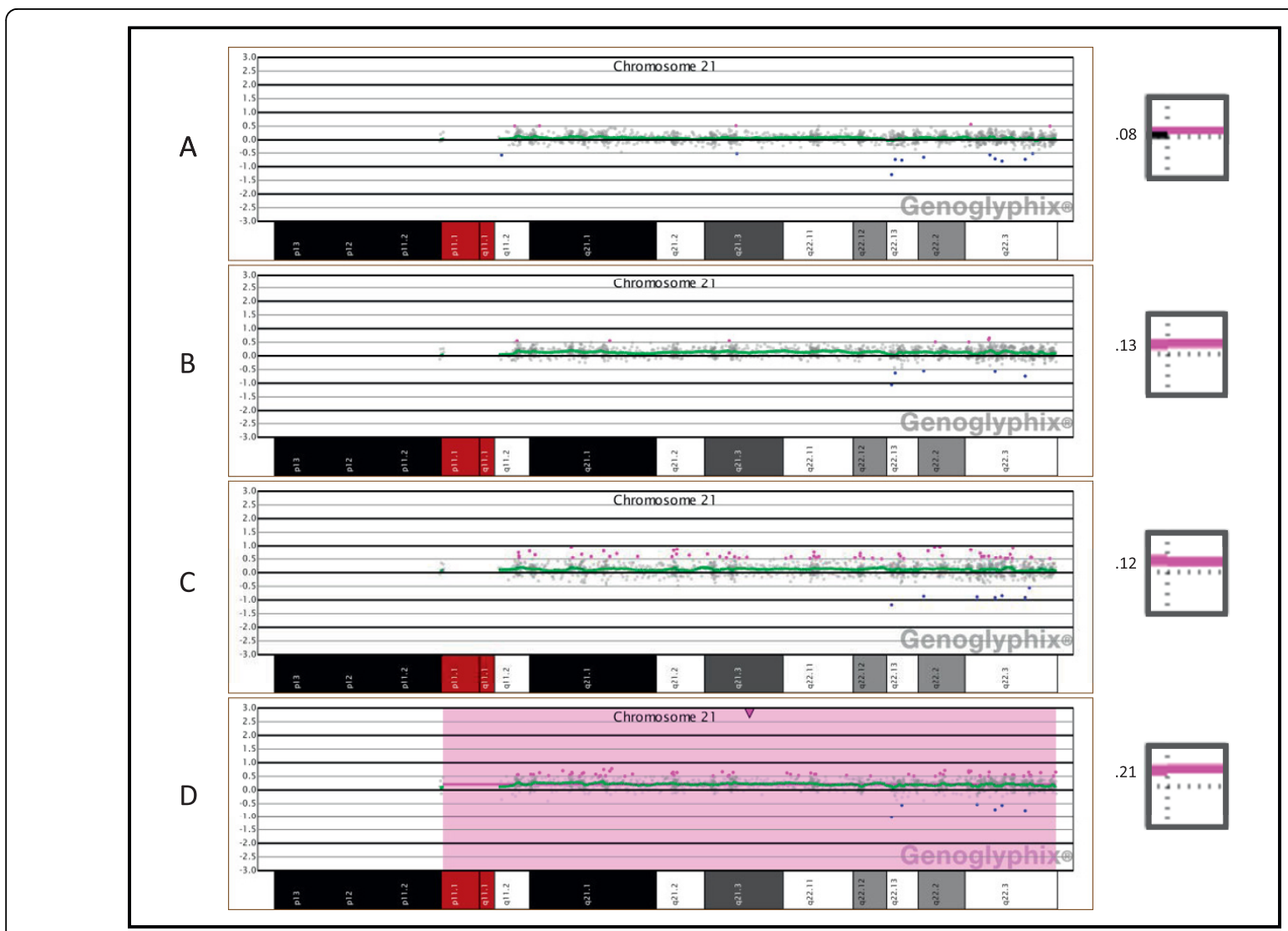

Figure 3 Oligonucleotide microarray analysis of artificially derived mosaic trisomy $\mathbf{2 1}$ samples. (A) 10\% trisomy 21 showing a very subtle copy-number gain for all clones on chromosome 21. The profile was generated using DNA extracted from a mixture of blood which contained 10\% WBCs from a trisomy 21 subject and 90\% WBCs from a normal male individual. (B) 15\% trisomy 21, generated as in (A), showing a very subtle copy-number gain for all clones on chromosome 21. (C) $20 \%$ trisomy 21 , generated as in (A) showing a subtle copy-number gain for all clones on chromosome 21. (D) 30\% trisomy 21, generated as in (A), showing a clear copy-number gain for all clones on chromosome 21. The inset images to the right of each array plot show the average $\log _{2}$ ratio of all probes mapping to chromosome 21 , with the horizontal dotted line representing a $\log _{2}$ ratio of zero and the vertical dotted line representing the centromere. A pink bar plotted above the horizontal line represents a copy-number gain of all probes on chromosome 21. To the left of each inset image is the average $\log _{2}$ ratio at the specified proportion of trisomic cells.

2.9 $\mathrm{Mb}$ deletion is likely to be clinically significant, it lies within a gap in the coverage of our BAC array and could only be detected using the oligo platform because of its more uniform backbone coverage.

The detection rate of alterations of unclear clinical significance is also a concern during the selection of a microarray platform in a clinical diagnostic setting. Our data suggest that both the oligo and BAC platforms detect similar numbers of abnormalities of unclear significance ( $7.0 \%$ by BAC and $7.1 \%$ by oligo), although the circumstances leading to an unclear clinical interpretation may vary between the platforms. On the BAC platform, unclear results are often associated with gaps in coverage which prevent the precise determination of the breakpoints and gene content of an abnormal region. This lack of information prohibits definitive interpretation of the clinical significance of the alteration. Figure 6 presents a $262 \mathrm{~kb}$ deletion of $9 \mathrm{q} 33.1$ detected by BAC array in a patient referred for developmental delay, dysmorphic features, and multiple congenital anomalies. The boundaries of this alteration as defined by BAC array include only one gene, TLR4 [25]. However, gaps in BAC coverage on both sides of the alteration span $4.5 \mathrm{Mb}$ proximally and $4.0 \mathrm{Mb}$ distally. As a result of these coverage gaps, this alteration, though estimated to be just $262 \mathrm{~kb}$, may be as large as $8.7 \mathrm{Mb}$ and include up to 48 additional genes. The design of BAC arrays with dense clone coverage is possible; however, probe density is limited by the availability of BAC clones and the presence of potentially interfering genomic architecture such as segmental duplications. In addition, BACbased microarrays will not reliably detect abnormalities smaller than the size of an individual probe- $80-200 \mathrm{~kb}$, on average, for BAC clones. 
Table 5 Mosaic Alterations Detected in the Prospective Diagnostic Comparison

\begin{tabular}{|c|c|c|}
\hline Pt. \# & $\begin{array}{l}\text { Proportion } \\
\quad(\%)\end{array}$ & Classification \\
\hline \multicolumn{3}{|l|}{ BAC } \\
\hline 25885 & 10 & $45, x$ \\
\hline 25838 & 10 & $47, X X, i(12)(p 10)$ \\
\hline 27745 & 10 & $46, X Y, \operatorname{trp}(12)(p 13.33 p 10)$ \\
\hline 26912 & 18 & $47, X Y, i(8)(p 10)$ \\
\hline 26358 & 20 & 46,XX,dup(2)(p14p11.2) \\
\hline 26880 & 24 & $47, X X,+9$ \\
\hline 23302 & 27 & $47, X X,+\operatorname{der}(9)(p 21.2 q 11)$ \\
\hline 23919 & 46 & $47, X Y,+\operatorname{der}(12)(p 13.33 q 11)$ \\
\hline 26127 & 53 & 46,XY,del(18)(q22.3q23) \\
\hline 26750 & 57 & $47, X Y,+\operatorname{der}(8)(p 11.22 q 11)$ \\
\hline 26894 & 60 & $45, x$ \\
\hline 24887 & 70 & $\begin{array}{l}\text { 46,XX,der(14)dup(14)(q32.13q32.2)del(14) } \\
\text { (q32.3q32.33) }\end{array}$ \\
\hline 23159 & 70 & $47, X Y Y$ \\
\hline 23155 & 77 & 46,XX,idic(18)(q21.33) \\
\hline 23215 & 87 & $47, X X,+21$ \\
\hline 25862 & 93 & $48, X X,+\operatorname{der}(13)($ pterq12.12), $+\operatorname{der}(20)(p 11.21 q 11)$ \\
\hline \multicolumn{3}{|l|}{ Oligo } \\
\hline 27978 & 21 & $\begin{array}{l}\text { 48,XY,+der(13)(pterq12.11),+der(?)(?::Xp22.31- } \\
>\text { Xp22.31::Xp22.2-> Xp22.12::?->cen->?) }\end{array}$ \\
\hline 32047 & 27 & $47, X X Y$ \\
\hline 32374 & 27 & $46, X X, r(X)(p 11.1 q 21.1)$ \\
\hline 32875 & 33 & $47, X Y,+\operatorname{inv} \operatorname{dup}(22)(q 11.21)$ \\
\hline 29361 & 53 & $47, X X,+\operatorname{der}(11)(\mathrm{p} 11.2 q 11)$ \\
\hline 31439 & 63 & $\begin{array}{l}\text { 47,XY,+der(12)(:p13.33::p13.31->p13.2::p11.23:: } \\
\text { p11.22->p11.21::?->12cen->?::p11.21->p11.22:. } \\
\text { p11.23::p13.2->::p13.31::p13.33:) }\end{array}$ \\
\hline 31633 & 63 & $48, X X,+\operatorname{der}(4)(p 13 q 12),+\operatorname{der}(13)($ pterq12.11) \\
\hline 30028 & 77 & 46,XY, del(7)(q22.1q22.3), del(12)(q21.31q22) \\
\hline 31336 & 80 & 46,XX,idic $(X)(q 21.1)$ \\
\hline 27105 & 90 & $47, X X,+\operatorname{der}(13)($ pterq12.12) \\
\hline 29786 & 90 & $46, X,+\operatorname{der}(X)(p 11.21 q 11.1)$ \\
\hline 30218 & 93 & $47, X Y,+\operatorname{der}(17)(p 11 q 11.2)$ \\
\hline
\end{tabular}

Although gaps in coverage and limited breakpointresolving power are primarily a concern for BAC platforms, both oligo and BAC platforms produce results that are unclear because a lack of published evidence prevents a conclusive association between the gene content of an alteration and the clinical features of the patient from being made. Figure 7 presents a $160 \mathrm{~kb}$ deletion of 4q25 detected by oligo array in a patient referred for developmental delay. Follow-up analysis performed on this patient's parents revealed that this alteration was de novo in origin. This alteration deletes two genes, PAPSS1 and SGMS2. While mutations or alterations of these genes have not been associated with disease in humans, it has been shown that PAPSS1 plays a key role in post-translational modification and SGMS2 mediates the production of sphingomyelin [26,27]. Thus, although the gene content and inheritance pattern of this deletion suggest a causative role in the patient's clinical features, a lack of published information linking the genes affected by this alteration with a distinct phenotype prevents a clear interpretation from being made based on only aCGH results. This type of unclear result, although more prominent with oligo platforms ( $4.2 \%$ by BAC vs. 7.1\% by oligo), is an element of all aCGH analysis regardless of platform and accentuates the need for databases containing aCGH results in combination with phenotypic information. Although the number of characterized genetic disorders and genomic regions is rapidly increasing, the clinical consequences of alterations involving much of the genome still remain unclear.

The increase in the number of copy number alterations identified by higher-resolution whole-genome arrays underscores the need for a variety of tools to facilitate the interpretation of array results in a clinical diagnostic setting. We propose the use of an algorithm such as the one outlined here in conjunction with databases of normal population variants, clinically significant alterations, and those of unclear significance. Although such databases can provide invaluable context for the analysis of aCGH data, care must be taken by the diagnostician when comparing their data to pre-existing databases of copy-number variations. For example, data in the DGV are pooled from a variety of sources, platforms, and populations using a variety of different controls and without independent verification, and thus may not be appropriate for comparison in all situations. Furthermore, recent evidence suggests that most data in the DGV overestimate the size of the regions involved because they are dependent primarily on BAC array data, which has a tendency to overestimate the true size of small aberrations [28]. Thus, the most useful CNV databases may be those generated by individual laboratories using identical reference controls and array platforms. Based on our experience, we have constructed a database of abnormal copy number aberrations identified by BAC and oligo aCGH in our laboratory and a database of copy-number variations thought to have no significance. Such databases are essential for understanding the various copy number aberrations identified by microarray analysis.

Genotype-phenotype correlations in a diagnostic setting must address a variety of factors including gene content, potential position effects, aberration size, and inheritance patterns. These factors often present conflicting evidence about the potential clinical significance of a rare alteration. For instance, the size of an abnormality is 


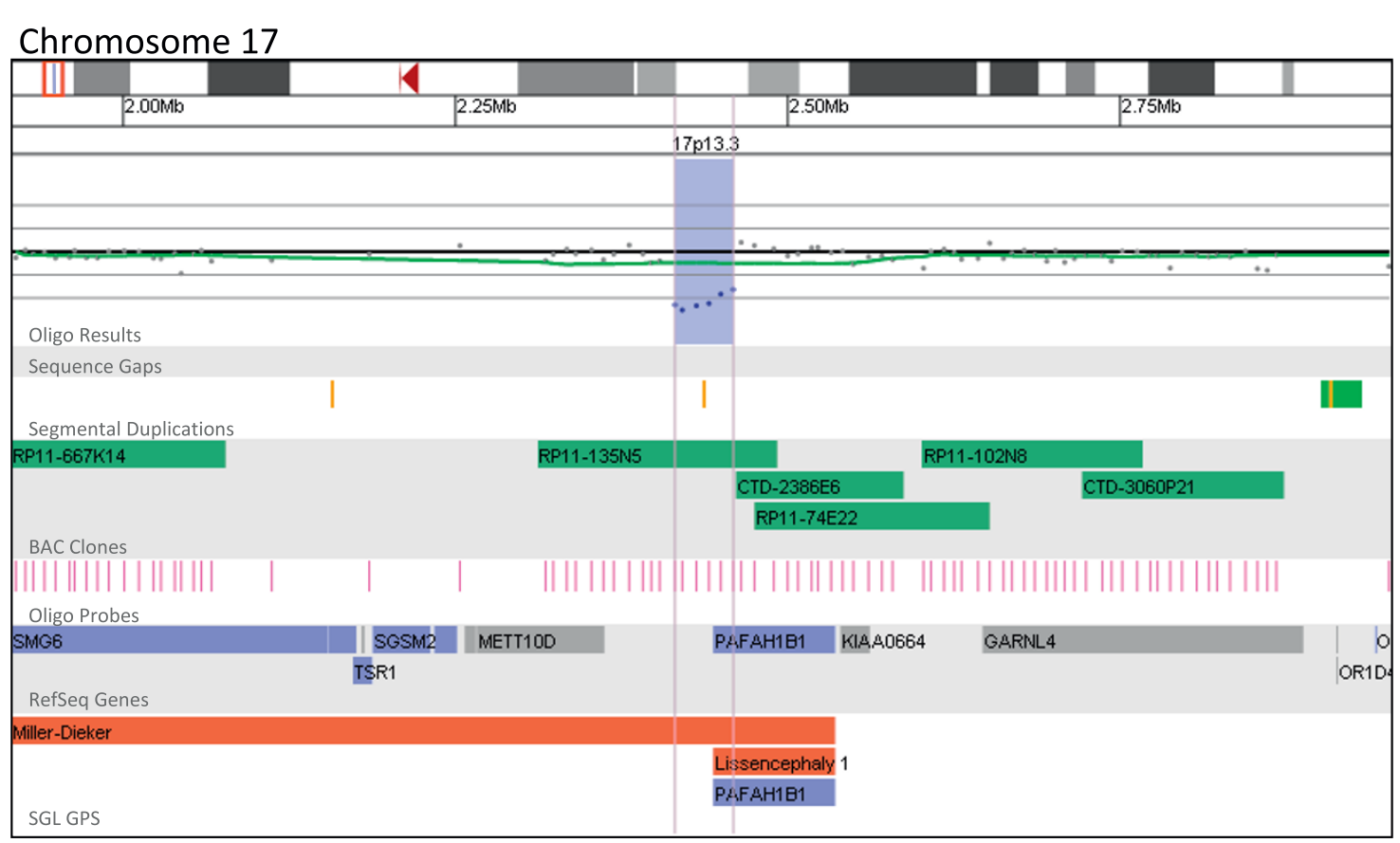

Figure 4 Oligonucleotide microarray characterization of an interstitial deletion at 17p13.3. The zoomed-in microarray plot shows a singlecopy loss of six probes from the short arm of chromosome 17 at 17p13.3, approximately $44.0 \mathrm{~kb}$ in size (chr17: 2,415,074-2,459,051, based on UCSC 2006 hg 18 assembly). Probes are ordered on the $x$ axis according to physical mapping positions, with the most distal 17p13.3 probes to the left and the most proximal 17p13.3 probes to the right. Below is a schematic of the deletion region. The deletion disrupts the PAFAH1B1/ LIS1 gene.

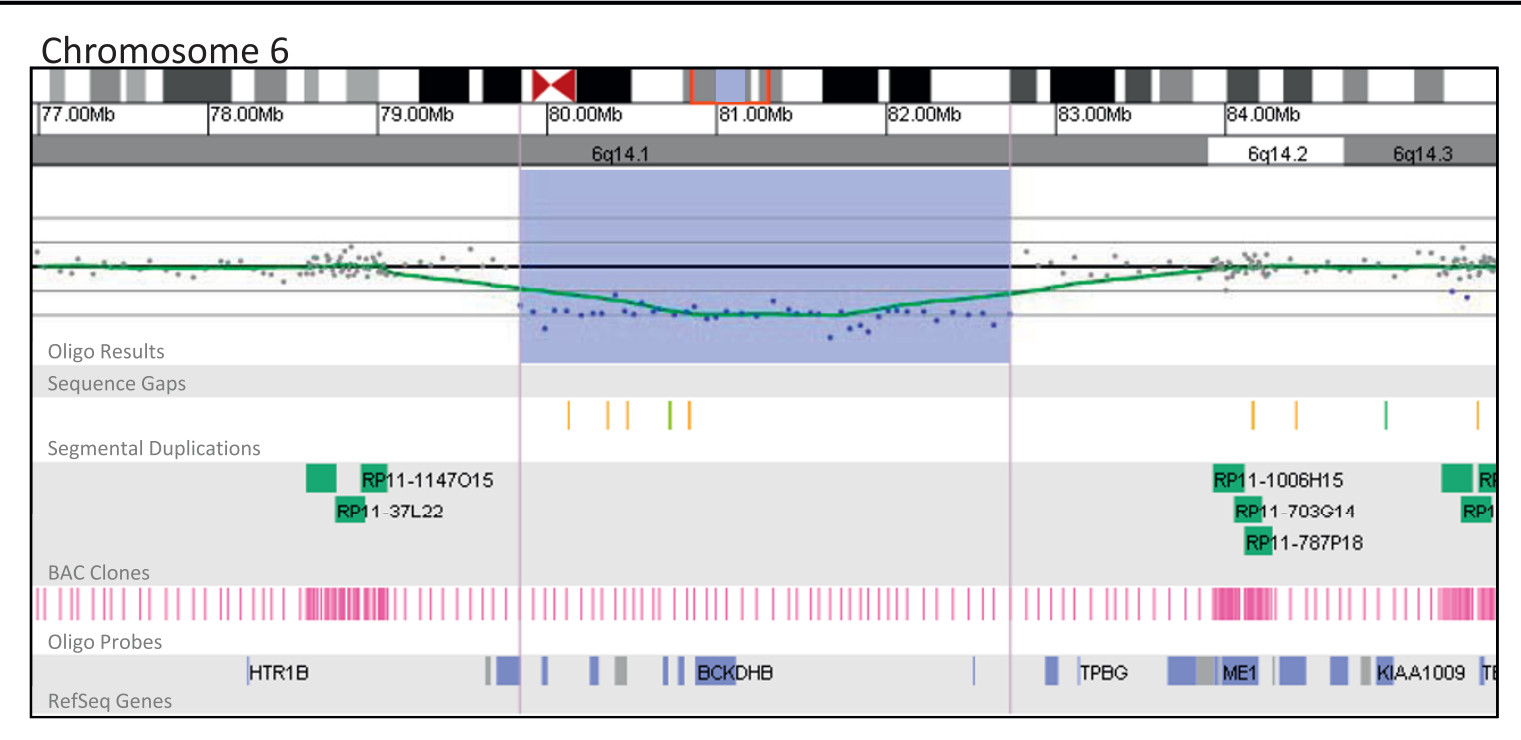

Figure 5 Oligonucleotide microarray characterization of an interstitial deletion at $\mathbf{6 q 1 4 . 1}$. The zoomed-in microarray plot shows a singlecopy loss of 43 oligonucleotide probes from the long arm of chromosome 6 at $6 q 14.1$, approximately $2.9 \mathrm{Mb}$ in size (chr6: 79,838,518$82,730,466$, based on UCSC 2006 hg 18 assembly). Probes are ordered on the $x$ axis according to physical mapping positions, with the most proximal $6 q 14.1$ probes to the left and the most distal $6 q 14.1$ probes to the right. Below is a schematic of the deletion region. Blue and gray boxes represent genes in the deletion region. 


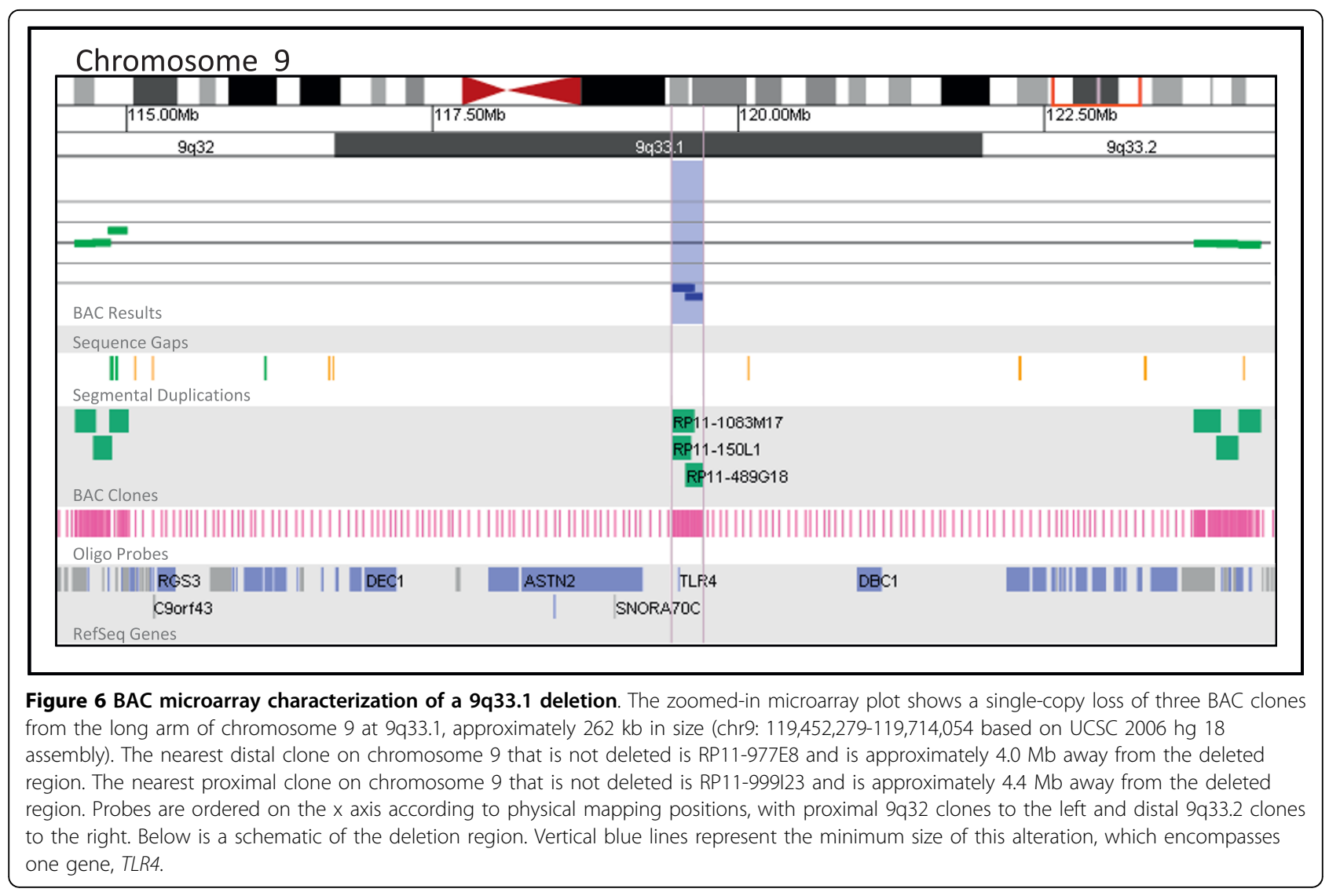

commonly used as justification for its proposed clinical consequences; however, this association is not always straightforward. High-resolution microarray analysis routinely detects abnormalities smaller than $500 \mathrm{~kb}$ that disrupt clinically significant genes and have clear phenotypic impact (Figure 4); conversely, numerous examples of common copy-number variants have been observed that are relatively large but lie in regions with sparse gene content. In addition, although it is generally assumed that de novo abnormalities are causative and inherited abnormalities are not, this is not always the case. There are a number of regions of the genome where both inherited and de novo copy number alterations have been identified, some of which result in mild phenotypes that may be inherited from parents who have a milder or subclinical, presentation. For example, deletions of distinct regions of 1q21 have been associated with both thrombocytopenia absent radius (TAR) syndrome and a variable phenotype including microcephaly/ macrocephaly, developmental delay, cardiac abnormalities, and schizophrenia [29-31], but in many instances aberrations of these regions are inherited from phenotypically normal parents [32]. Another example is the 16 p11.2 region associated with a range of cognitive, developmental, and speech delays, behavioral issues, and autism, deletions and duplications of which can be inherited or de novo [33-36]. In regions such as these, copy number changes may unmask recessive alleles or work in conjunction with various genetic modifiers, perhaps even other CNVs, to produce a clinical phenotype. Potentially, non-paternity may also confound genotype-phenotype correlation for copy number alterations in these complex regions of the genome. These reasons underscore the need for thorough databases of normal population variants and clinically significant alterations complete with genotype-phenotype correlations. Such databases expedite the process of determining the potential significance of copy-number alterations in a diagnostic setting; aid in the elucidation of new microdeletion/duplication syndromes and new regions of benign copy-number variation; and help reduce the burden of expensive, timeconsuming, and difficult follow-up necessitated by the increased number of alterations of unclear clinical significance detected by microarray analysis.

We [19] and others [37] have shown that mosaicism can be detected at low frequencies of chromosomally abnormal cells using BAC-based aCGH; however, the ability of oligo platforms to reliably detect mosaic abnormalities has not yet been well established. Our current assessments demonstrate that aCGH using 


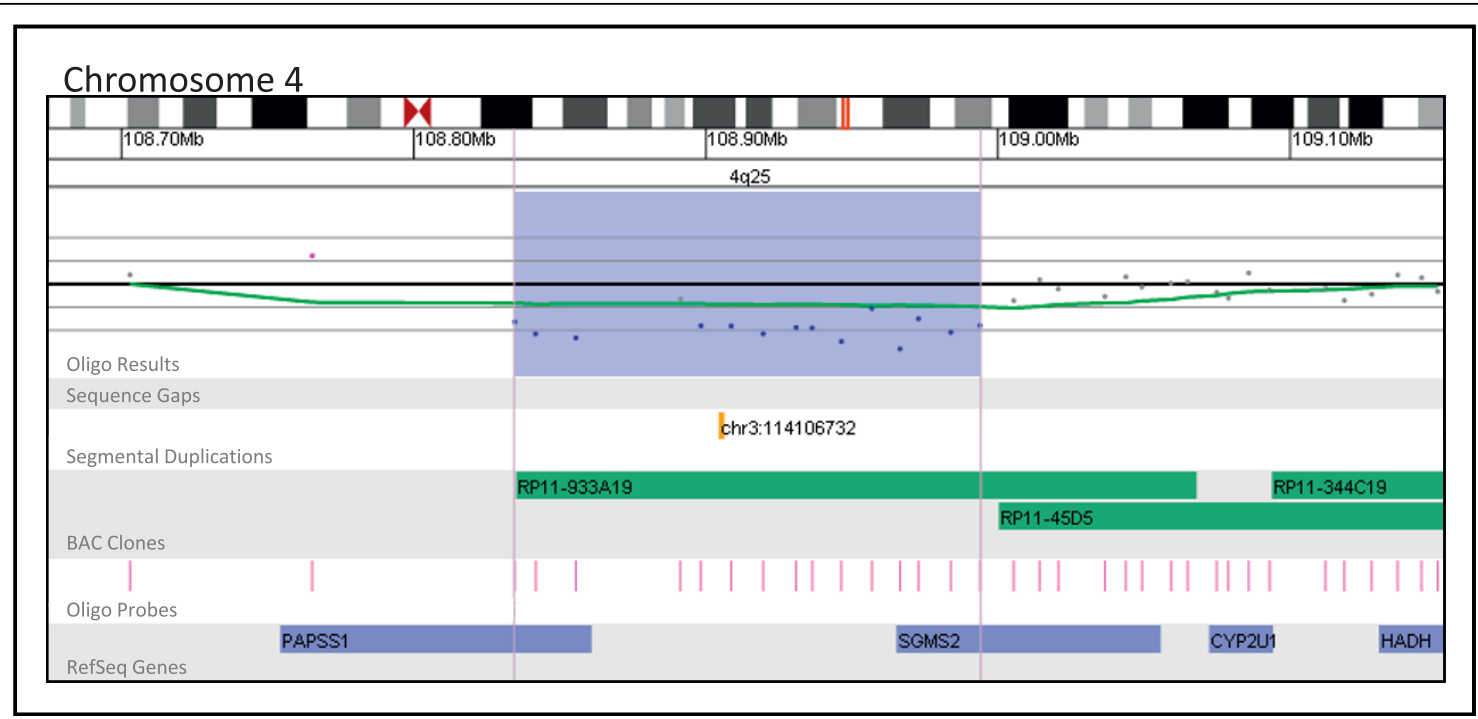

Figure $\mathbf{7}$ Oligonucleotide microarray characterization of an interstitial deletion at $\mathbf{4 q 2 5}$. The zoomed-in microarray plots shows a singlecopy loss of 15 oligonucleotide probes from the long arm of chromosome 4 at 4q25, approximately $159.6 \mathrm{~kb}$ in size (chr4: 108,834,399108,994,048, based on UCSC 2006 hg 18 assembly). Probes are ordered on the $x$ axis according to physical mapping positions, with proximal $4 q 25$ clones to the left and distal $4 \mathrm{q} 25$ clones to the right. Below is a schematic of the deletion region. The deletion disrupts the PAPSS1 and SGMS2 genes, represented by blue boxes.

either BAC or oligo platforms can easily detect mosaicism of $30 \%$ or greater for a variety of alterations and that levels as low as $10 \%$ can be detected with both platforms under optimal conditions. In addition, our retrospective analysis showed that there is no significant difference between the two types of platforms in the number of mosaic abnormalities detected in a clinical diagnostic setting $(\mathrm{p}=0.7066)$. However, BAC-based arrays may still have a greater ability to detect mosaic abnormalities present at very low levels (less than 20\%), perhaps due to the routine use of dye-swap experiments which can be cost-prohibitive with oligo arrays but promote the visual identification of mosaic abnormalities. The sensitivity of the BAC array is demonstrated by the detection in three cases of abnormalities in only $10 \%$ of cells during the retrospective study, whereas the lowest level of mosaicism detected by our oligo array was $21 \%$ (Table 5). The ability of an aCGH platform to detect mosaic abnormalities also depends largely on the effectiveness of the software used to analyze the data, as low-level mosaic alterations are difficult to identify using only visual inspection (Figure 3). For this reason, it is important to select analysis software which facilitates the identification of mosaic alterations.

These data suggest high-resolution oligo-based aCGH detects a higher proportion of clinically significant abnormalities than BAC-based aCGH. Our results also demonstrate the ability of microarray-based CGH to reliably produce high-yield results in a clinical setting using differing platforms, array designs, and analysis algorithms, supporting the validity of array CGH as a first-tier diagnostic screening tool [38]. Finally, the prevalence of copy number variants of unclear clinical significance detected on both platforms underscores the need for the development of readily accessible diagnostic tools in the form of databases of documented chromosome abnormalities to aid in the interpretation of microarray data.

\section{Acknowledgements}

We thank Aaron Theisen (Signature Genomic Laboratories, Spokane, WA) for his careful edits of the paper and all of the laboratory staff at Signature Genomics for conducting the aCGH and FISH experiments.

\section{Authors' contributions}

NN wrote the manuscript; BST analyzed the molecular cytogenetics results; $B A B, B C B$ and LGS designed and coordinated the study. All authors have read and approved the final manuscript.

\section{Competing interests}

NN, BST, BCB, BAB and LGS are employees of Signature Genomic Laboratories, a subsidiary of PerkinElmer.

Received: 16 March 2010 Accepted: 29 June 2010

Published: 29 June 2010

\section{References}

1. Shaffer LG, Bejjani BA, Torchia B, Kirkpatrick S, Coppinger J, Ballif BC: The identification of microdeletion syndromes and other chromosome abnormalities: Cytogenetic methods of the past, new technologies for the future. Am J Med Genet C Semin Med Genet 2007, 145C:335-345.

2. Shevell MI, Bejjani BA, Srour M, Rorem EA, Hall N, Shaffer LG: Array comparative genomic hybridization in global developmental delay. Am J Med Genet B Neuropsychiatr Genet 2008, 147B:1101-1108.

3. Ballif BC, Hornor SA, Jenkins E, Madan-Khetarpal S, Surti U, Jackson KE, Asamoah A, Brock PL, Gowans GC, Conway RL, Graham JM Jr, Medne L, Zackai EH, Shaikh TH, Geoghegan J, Selzer RR, Eis PS, Bejjani BA, Shaffer LG: 
Discovery of a previously unrecognized microdeletion syndrome of 16p11.2-p12.2. Nat Genet 2007, 39:1071-1073.

4. Ballif BC, Theisen A, McDonald-McGinn DM, Zackai EH, Hersh JH, Bejjani BA, Shaffer LG: Identification of a previously unrecognized microdeletion syndrome of 16q11.2q12.2. Clin Genet 2008, 74:469-475.

5. Koolen DA, Vissers LE, Pfundt R, de Leeuw N, Knight SJ, Regan R, Kooy RF, Reyniers E, Romano C, Fichera M, Schinzel A, Baumer A, Anderlid BM, Schoumans J, Knoers NV, van Kessel AG, Sistermans EA, Veltman JA, Brunner HG, de Vries BB: A new chromosome 17q21.31 microdeletion syndrome associated with a common inversion polymorphism. Nat Genet 2006, 38:999-1001.

6. Sharp AJ, Hansen S, Selzer RR, Cheng Z, Regan R, Hurst JA, Stewart H, Price SM, Blair E, Hennekam RC, Fitzpatrick CA, Segraves R, Richmond TA, Guiver C, Albertson DG, Pinkel D, Eis PS, Schwartz S, Knight SJ, Eichler EE: Discovery of previously unidentified genomic disorders from the duplication architecture of the human genome. Nat Genet 2006, 38:1038-1042.

7. Sharp AJ, Selzer RR, Veltman JA, Gimelli S, Gimelli G, Striano P, Coppola A, Regan R, Price SM, Knoers NV, Eis PS, Brunner HG, Hennekam RC, Knight SJ, de Vries BB, Zuffardi O, Eichler EE: Characterization of a recurrent 15q24 microdeletion syndrome. Hum Mol Genet 2007, 16:567-572.

8. Shaw-Smith C, Pittman AM, Willatt L, Martin H, Rickman L, Gribble S, Curley R, Cumming S, Dunn C, Kalaitzopoulos D, Porter K, Prigmore E, Krepischi-Santos AC, Varela MC, Koiffmann CP, Lees AJ, Rosenberg C, Firth HV, de Silva R, Carter NP: Microdeletion encompassing MAPT at chromosome $17 \mathrm{q} 21.3$ is associated with developmental delay and learning disability. Nat Genet 2006, 38:1032-1037.

9. Vissers LE, van Ravenswaaij CM, Admiraal R, Hurst JA, de Vries BB, Janssen IM, van der Vliet WA, Huys EH, de Jong PJ, Hamel BC Schoenmakers EF, Brunner HG, Veltman JA, van Kessel AG: Mutations in a new member of the chromodomain gene family cause CHARGE syndrome. Nat Genet 2004, 36:955-957.

10. Sharp AJ: Emerging themes and new challenges in defining the role of structural variation in human disease. Hum Mutat 2009, 30:135-144.

11. Cytrynbaum CS, Smith AC, Rubin T, Weksberg R: Advances in overgrowth syndromes: clinical classification to molecular delineation in Sotos syndrome and Beckwith-Wiedemann syndrome. Curr Opin Pediatr 2005, 17:740-746.

12. Gropman AL, Elsea S, Duncan WC Jr, Smith AC: New developments in Smith-Magenis syndrome (del 17p11.2). Curr Opin Neurol 2007, 20:125-134.

13. Ballif BC, Theisen A, Coppinger J, Gowans GC, Hersh JH, Madan-Khetarpal S, Schmidt KR, Tervo R, Escobar LF, Friedrich CA, McDonald M, Campbell L Ming JE, Zackai EH, Bejjani BA, Shaffer LG: Expanding the clinical phenotype of the $3 q 29$ microdeletion syndrome and characterization of the reciprocal microduplication. Mol Cytogenet 2008, 1:8.

14. Coppinger J, McDonald-McGinn D, Zackai E, Shane K, Atkin JF, Asamoah A, Leland R, Weaver DD, Lansky-Shafer S, Schmidt K, Feldman H, Cohen W, Phalin J, Powell B, Ballif BC, Theisen A, Geiger E, Haldeman-Englert C, Shaikh TH, Saitta S, Bejjani BA, Shaffer LG: Identification of familial and de novo microduplications of 22q11.21-q11.23 distal to the 22q11.21 microdeletion syndrome region. Hum Mol Genet 2009, 18:1377-1383.

15. Shaffer $L G$, Theisen A, Bejjani BA, Ballif BC, Aylsworth AS, Lim C, McDonald M, Ellison JW, Kostiner D, Saitta S, Shaikh T: The discovery of microdeletion syndromes in the post-genomic era: review of the methodology and characterization of a new 1q41q42 microdeletion syndrome. Genet Med 2007, 9:607-616.

16. Bejjani BA, Saleki R, Ballif BC, Rorem EA, Sundin K, Theisen A, Kashork CD, Shaffer LG: Use of targeted array-based CGH for the clinical diagnosis of chromosomal imbalance: Is less more? Am J Med Genet A 2005, 134:259-267.

17. Bejjani $B A$, Shaffer $L G$, Ballif $B C$ : The use of microarray technology for cytogenetics. Methods Mol Biol 2010, 632:125-139.

18. Traylor RN, Fan Z, Hudson B, Rosenfeld JA, Shaffer LG, Torchia BS, Ballif BC: Microdeletion of $6 \mathrm{q} 16.1$ encompassing EPHA7 in a child with mild neurological abnormalities and dysmorphic features: case report. $\mathrm{Mol}$ Cytogenet 2009, 2:17.

19. Ballif BC, Rorem EA, Sundin K, Lincicum M, Gaskin S, Coppinger J, Kashork CD, Shaffer LG, Bejjani BA: Detection of low-level mosaicism by array CGH in routine diagnostic specimens. Am J Med Genet A 2006, 140:2757-2767.
20. Lo Nigro C, Chong CS, Smith AC, Dobyns WB, Carrozzo R, Ledbetter DH: Point mutations and an intragenic deletion in LIS1, the lissencephaly causative gene in isolated lissencephaly sequence and Miller-Dieker syndrome. Hum Mol Genet 1997, 6:157-164.

21. Williams SN, Locke CJ, Braden AL, Caldwell KA, Caldwell GA: Epileptic-like convulsions associated with LIS-1 in the cytoskeletal control of neurotransmitter signaling in Caenorhabditis elegans. Hum Mol Genet 2004, 13:2043-2059.

22. Chuang JL, Wynn RM, Moss CC, Song JL, Li J, Awad N, Mandel H, Chuang DT: Structural and biochemical basis for novel mutations in homozygous Israeli maple syrup urine disease patients: a proposed mechanism for the thiamin-responsive phenotype. J Biol Chem 2004, 279:17792-17800.

23. Edelmann L, Wasserstein MP, Kornreich R, Sansaricq C, Snyderman SE, Diaz GA: Maple syrup urine disease: identification and carrier-frequency determination of a novel founder mutation in the Ashkenazi Jewish population. Am J Hum Genet 2001, 69:863-868.

24. Nobukuni Y, Mitsubuchi H, Akaboshi I, Indo Y, Endo F, Yoshioka A Matsuda I: Maple syrup urine disease. Complete defect of the E1 beta subunit of the branched chain alpha-ketoacid dehydrogenase complex due to a deletion of an 11-bp repeat sequence which encodes a mitochondrial targeting leader peptide in a family with the disease. J Clin Invest 1991, 87:1862-1866.

25. Poltorak A, He X, Smirnova I, Liu MY, Van Huffel C, Du X, Birdwell D, Alejos E, Silva M, Galanos C, Freudenberg M, Ricciardi-Castagnoli P, Layton B, Beutler B: Defective LPS signaling in C3H/HeJ and C57BL/ 10ScCr mice: mutations in Tlr4 gene. Science 1998, 282:2085-2088.

26. Huitema K, van den Dikkenberg J, Brouwers JF, Holthuis JC: Identification of a family of animal sphingomyelin synthases. EMBO J 2004, 23:33-44.

27. Xu ZH, Otterness DM, Freimuth RR, Carlini EJ, Wood TC, Mitchell S, Moon E, Kim UJ, Xu JP, Siciliano MJ, Weinshilboum RM: Human 3'phosphoadenosine $5^{\prime}$-phosphosulfate synthetase 1 (PAPSS1) and PAPSS2: gene cloning, characterization and chromosomal localization. Biochem Biophys Res Commun 2000, 268:437-444.

28. Bailey JA, Kidd JM, Eichler EE: Human copy number polymorphic genes. Cytogenet Genome Res 2008, 123:234-243.

29. Brunetti-Pierri N, Berg JS, Scaglia F, Belmont J, Bacino CA, Sahoo T, Lalani SR, Graham B, Lee B, Shinawi M, Shen J, Kang SH, Pursley A, Lotze T, Kennedy G, Lansky-Shafer S, Weaver C, Roeder ER, Grebe TA, Arnold GL, Hutchison T, Reimschisel T, Amato S, Geragthy MT, Innis JW, Obersztyn E, Nowakowska B, Rosengren SS, Bader PI, Grange DK, et al: Recurrent reciprocal 1q21.1 deletions and duplications associated with microcephaly or macrocephaly and developmental and behavioral abnormalities. Nat Genet 2008, 40:1466-1471.

30. Stefansson H, Rujescu D, Cichon S, Pietilainen OP, Ingason A, Steinberg $S$, Fossdal R, Sigurdsson E, Sigmundsson T, Buizer-Voskamp JE, Hansen T, Jakobsen KD, Muglia P, Francks C, Matthews PM, Gylfason A, Halldorsson BV, Gudbjartsson D, Thorgeirsson TE, Sigurdsson A, Jonasdottir A, Bjornsson A, Mattiasdottir S, Blondal T, Haraldsson M, Magnusdottir BB, Giegling I, Moller HJ, Hartmann A, Shianna KV, et al: Large recurrent microdeletions associated with schizophrenia. Nature 2008, 455:232-236.

31. Klopocki E, Schulze H, Strauss G, Ott CE, Hall J, Trotier F, Fleischhauer S, Greenhalgh L, Newbury-Ecob RA, Neumann LM, Habenicht R, Konig R, Seemanova E, Megarbane A, Ropers HH, Ullmann R, Horn D, Mundlos S: Complex inheritance pattern resembling autosomal recessive inheritance involving a microdeletion in thrombocytopenia-absent radius syndrome. Am J Hum Genet 2007, 80:232-240.

32. Mefford HC, Sharp AJ, Baker C, Itsara A, Jiang Z, Buysse K, Huang S, Maloney VK, Crolla JA, Baralle D, Collins A, Mercer C, Norga K, de Ravel T, Devriendt K, Bongers EM, de Leeuw N, Reardon W, Gimelli S, Bena F, Hennekam RC, Male A, Gaunt L, Clayton-Smith J, Simonic I, Park SM, Mehta SG, Nik-Zainal S, Woods CG, Firth HV, et al: Recurrent rearrangements of chromosome 1q21.1 and variable pediatric phenotypes. N Engl J Med 2008, 359:1685-1699.

33. Kumar RA, KaraMohamed S, Sudi J, Conrad DF, Brune C, Badner JA, Gilliam TC, Nowak NJ, Cook EH Jr, Dobyns WB, Christian SL: Recurrent 16p11.2 microdeletions in autism. Hum Mol Genet 2008, 17:628-638.

34. Marshall CR, Noor A, Vincent JB, Lionel AC, Feuk L, Skaug J, Shago M, Moessner R, Pinto D, Ren Y, Thiruvahindrapduram B, Fiebig A, Schreiber S, Friedman J, Ketelaars CE, Vos YJ, Ficicioglu C, Kirkpatrick S, Nicolson R, 
Sloman L, Summers A, Gibbons CA, Teebi A, Chitayat D, Weksberg R, Thompson A, Vardy C, Crosbie V, Luscombe S, Baatjes R, et al: Structural variation of chromosomes in autism spectrum disorder. Am J Hum Genet 2008, 82:477-488.

35. Weiss LA, Shen Y, Korn JM, Arking DE, Miller DT, Fossdal R, Saemundsen E, Stefansson H, Ferreira MA, Green T, Platt OS, Ruderfer DM, Walsh CA,

Altshuler D, Chakravarti A, Tanzi RE, Stefansson K, Santangelo SL, Gusella JF, Sklar P, Wu BL, Daly MJ: Association between microdeletion and microduplication at 16p11.2 and autism. N Engl J Med 2008, 358:667-675.

36. Rosenfeld JA, Coppinger J, Bejjani BA, Girirajan S, Eichler EE, Shaffer LG, Ballif BC: Speech Delays and Behavioral Problems are the Predominant Features in Individuals with Developmental Delays and 16p11.2 Microdeletions and Microduplications. J Neurodev Disord 2009, 0:1-13.

37. Cheung SW, Shaw CA, Scott DA, Patel A, Sahoo T, Bacino CA, Pursley A, Li J, Erickson R, Gropman AL, Miller DT, Seashore MR, Summers AM, Stankiewicz P, Chinault AC, Lupski JR, Beaudet AL, Sutton VR, et al: Microarray-based CGH detects chromosomal mosaicism not revealed by conventional cytogenetics. Am J Med Genet A 2007, 143:1679-1686.

38. Miller DT, Adam MP, Aradhya S, Biesecker LG, Brothman AR, Carter NP, Church DM, Crolla JA, Eichler EE, Epstein CJ, Faucett WA, Feuk L, Friedman JM, Hamosh A, Jackson L, Kaminsky EB, Kok K, Krantz ID, Kuhn RM, Lee C, Ostell JM, Rosenberg C, Scherer SW, Spinner NB, Stavropoulos DJ, Tepperberg JH, Thorland EC, Vermeesch JR, Waggoner DJ, Watson MS, et al: Consensus statement: chromosomal microarray is a first-tier clinical diagnostic test for individuals with developmental disabilities or congenital anomalies. Am J Hum Genet 86:749-764.

doi:10.1186/1755-8166-3-11

Cite this article as: Neill et al:: Comparative analysis of copy number detection by whole-genome BAC and oligonucleotide array CGH.

Molecular Cytogenetics 2010 3:11.

\section{Submit your next manuscript to BioMed Central and take full advantage of:}

- Convenient online submission

- Thorough peer review

- No space constraints or color figure charges

- Immediate publication on acceptance

- Inclusion in PubMed, CAS, Scopus and Google Scholar

- Research which is freely available for redistribution

Submit your manuscript at www.biomedcentral.com/submit 